\title{
Wolf in Sheep's Clothing: Extreme Right- Wing Ideologies in Australian Black Metal
}

\author{
Benjamin Philip Hillier \\ University of Tasmania \\ Benjamin.Hillier@utas.edu.au
}

\author{
Ash Barnes \\ University of Tasmania \\ ashleigh.barnes@utas.edu.au
}

\begin{abstract}
Abstract: This paper will examine the presence of extreme right-wing ideologies in the Australian black metal bands Spear of Longinus and Deströyer 666. We demonstrate how the album artwork, lyrics, and live performances of these bands reflect, influence, and communicate the ideological and political opinions of band members. Our focus is on the strategic conveyance of ultra-nationalist, fascist and alt-right political views in Australian black metal. We combine this analysis of various texts and paratexts by these bands with an examination of how these bands justify the presence of extreme right-wing and political beliefs within their work, drawing on the frameworks of reflexive anti-reflexivity (KahnHarris, 2007) and black metal as Gesamtkunstwerk (Lesourd 2013). Finally, we show how fans of these bands deploy their songs as political tools when commenting on social issues, demonstrating that, regardless of the band's diffusion of blame, their extreme right-wing views become very real to the listener.
\end{abstract}

KEYWORDS: Australian extreme metal, fascism, black metal, popular music, reflexive antireflexivity

\section{Introduction}

This paper will examine how the album artworks, lyrics, and live performances of black metal bands in Australia reflect, influence, and communicate the fascist, ultranationalist and alt-right political opinions of band members. We posit that the 
ideological convictions of black metal musicians are intrinsic elements of the genre's artistic expression, as opposed to the view that they can be easily discarded or regarded as unimportant should the listener wish to do so. Thus, we argue that the communication of extreme right-wing ideologies and political views through the music of these bands is deeply problematic and cannot be removed from their artistic expression.

This paper will focus on two case studies that examine the bands Spear of Longinus and Deströyer 666. Using paratextual analysis and readings of their song lyrics and interviews, we capture and understand what ideologies are held by these artists and how these are communicated to and received by fans. This analysis specifically explores how these ideologies are expressed through music, coded language and symbols, and the personae of black metal performers. Often, this coded language takes a form colloquially referred to as 'dog-whistling' which refers to speaking in a way that a target audience understands your meaning while others remain unaware of the implications of your speech and symbols (Haney-Lopez 2015). Later sections of the paper will consider the interaction between ideology and genre, using a range of frameworks such as Kahn-Harris' reflexive antireflexivity (2007) and Lesourd's black metal as Gesamtkunstwerk (2013). These frameworks allow us to examine how such ideologies operate within their respective scenes and how the social infrastructure of the Australian black metal scene produces and sustains those who hold far right-wing political views. We will conclude by demonstrating the connection between the musical and the social through an examination of how these performers' views are deployed by their fans, reinforcing the link between alt-right political ideology and musical expression.

The investigators used a mixed-methods approach. This primarily includes paratextual analysis and close readings of a range of texts including songs, interviews, and social media releases. Paratextual analysis has been used by Eric Smialek (2015) in their study of extreme metal genres to demonstrate how these elements are of great importance to both bands and fans in communicating belonging within music cultures. Smialek notes that black metal is recognized equally through its paratexts and its musical features (2015: 30). While this paper is not exploring musicological analysis in the same depth as Smialek's work, it will nonetheless consider these paratexts as essential elements of the genre which influence descriptions and discussions of musical style (see Hillier 2020). Whilst some sociologists have taken deep personal risks to interview neo-Nazis by infiltration (Hamm 1993; Hamm and Spaaij 2017), we follow the tradition of others such as Potter (2005), Cotter (1999) and Brown (2004), who focus on the lyrical and historical relevance of neo-Nazi and fascist music. However, where relevant, our reading of texts and paratexts is further supplemented by interviews with members of the Australian metal scene as identified by the authors and the authors' own observations attending gigs and participating in metal and other alternative music scenes around Australia.

\section{Genre and ideology in Metal music}

Given that this paper closely considers the link between genre and ideology, the issue of genre itself is an important consideration. Correctly understanding and defining the various subgenres in metal music has long been recognized as a means of establishing authenticity and cultural capital within metal scenes (Kahn-Harris 2007; Thornton 1996; Threadgold 2015). Furthermore, certain genres are held to 
attract certain political ideologies. This is not a strict rule; across all political spectrums, bands will use lyrics that listeners may vehemently disagree with (Overell 2015). However, black metal as a broad genre is commonly noted to attract far-right political messages (Olsen 2011). Most notable is the subgenre National Socialist Black Metal (hereafter NSBM), which typically connotes bands who explicitly advocate for fascist politics in their music (Olsen 2011). For example, the split CD release Unsere Krieg ("Our War") (Acclaim Records/Ancient Legacy Productions, 2008) between the bands 88, Iron Youth 88 and Moloch features two uses of 88 , with 88 being a veiled reference to "Heil Hitler" (the logic behind this is that the eighth letter of the alphabet is $\mathrm{H}$, therefore $88=\mathrm{HH}=$ Heil Hitler). The band 88 stylizes their name with runes that resemble the flag of the Nazi Schutzstaffel (or SS), demonstrating how explicit NSBM bands are with their affiliations with neo-Nazi movements. Although violent, far-right ideologies are somewhat common in wider black metal scenes (and most infamously the Norwegian scene), only the most explicit and overt tend to be categorized as NSBM (Johnson and Cloonan 2009). Olsen (2011) notes that whilst NSBM bands hold racist ideologies, they are not marginal but highly influential in global black metal scenes. Nazi symbolism is appropriated for a hyper-transgression, defining and redefining the boundaries of transgression within black metal. We acknowledge that Nazism and similar extreme right-wing symbols are used in alternative music scenes to express transgression and to shock (see McNeil and McCain 1996) and contend in this paper that the discourse around fascist ideologies in black metal has more significant socio-political consequences.

\section{Contextualizing Australian metal}

Here, we must briefly summarize the history and development of the Australian metal scene to provide the context for our case studies. The Australian metal scene mainly developed out of hard rock and pub rock scenes in the 1980s, along with a substantial musical and cultural influence from global metal scenes (Phillipov 2008). While there are examples of proto-metal bands in Australia, such as Buffalo in the 1970s, the first true metal scene did not emerge until the 1980s, based in Melbourne (Calpakdijan 2014, Hillier 2019a). This scene gravitated around the Metal for Melbourne record store and consisted of classic heavy metal bands such as Taipan, S.A.S, and Ion Drive, who were heavily influenced by the New Wave of British Heavy Metal (hereafter NWOBHM). In spite of the marked stylistic influence from NWOBHM, Australian metal retained a marked cultural and aesthetic influence from Australian hard rock and pub rock bands who had been active throughout the 1970s and 1980s, manifesting in an attitude of larrikinism closely associated with white, male, working-class identities (Hoad 2019; Vallen 2019; Hillier 2019a; 2019b).

Extreme metal developed later in the 1980s, beginning with thrash metal bands such as Renegade, Mortal Sin, and Hobbs' Angel of Death. Similarly, Armoured Angel are frequently credited as the pioneers of Australian death metal, whilst Slaughter Lord are heavily reminiscent of the first wave black metal in the vein of Swedish band Bathory (Calpakdijan 2014; Giffin 2015). These bands would contribute to a broader scene that would serve as the basis for other subgenres. Australian extreme metal scenes are now characterized by genre hybridity rather than a single, unifying style, a trend that has continued into the current Australian extreme metal scene (Hillier 2018, 2019b). International connections and 
influences continued to exist between Australia and other global metal scenes. For example, the liner notes to Bathory's Under the Sign of The Black Mark (Under One Flag 1987), a landmark release for black metal, features a thank you note to Slaughter Lord, indicating that these stylistically similar bands were influenced by one another even though they were almost on opposite sides of the world. This is evident in the way musical styles (along with social ethics) influence each other, an impact that can transcend entire music scenes, as seen in the way American and British metal, punk and hardcore influenced modern Australian alternative music (Ensminger 2011; Hannon 2010). These examples demonstrate that from its earliest days Australia's metal scene has been built on a range of metal music genres, with influences from those across the world. While there are musical, ideological, and personal links between these Australian bands and international metal scenes that have similar ideological frameworks, this article will only consider how these views manifest in Australian bands and how their manifestation affects the wider Australian metal scene.

The cultural and ideological underpinnings of the Australian metal scene relate to wider Australian culture and constructions of race. Phillipov (2008) notes that Australian metal exists in a state of tension between the global and the local, and that it is unclear as to what is Australian about Australian extreme metal. They suggest that Australian metal bands tend to draw on "yobbo"(1) stereotypes and that the scene has developed a local and international reputation for producing especially extreme and/or brutal bands. Hoad (2016) extends Phillipov's points regarding race in Australian metal, looking at how whiteness is constructed in Australian metal scenes. Australian metal is characterized as "banal nationalism" that fetishizes "white sameness" and enables the exclusion of "Otherness" from (Australian) extreme metal. Australian metal scenes construct "Australianness" through a tacit reproduction of a hegemonic Australian identity. This is constructed around a central narrative which relies on national archetypes, with an emphasis on the white, masculine culture of the "everyday bloke" (Hoad 2016: 22-3). The Australian "everyday bloke" is internalized and expressed as a form of "larrikinism" (Hoad 2019; Vallen 2019; Hillier 2019b). An example of this is the expression of larrikinism within Australian surf culture, which is then embodied through metal, metalcore and hardcore bands such as Parkway Drive, who personify the "ideal" image of the Australian male (Whiting, Klimentou and Rogers 2019). Through prizing natural physical strength and prowess, hypermasculinity sustains most alternative music scenes, rendering them largely male dominated and disproportionally white (Driver 2016; Griffin 2012; Schilt 2014).

Whilst nationalism, whiteness and masculinity bring unique understandings of identity within Australian metal, the use of larrikinism injects an element of humour and non-seriousness into the Australian metal identity. As Vallen (2019) emphasizes, this allows significant themes present in music to become comical, "taking the piss", and therefore, not taken seriously by listeners and performers alike. The emphasis on larrikinism is especially problematic for bands that advocate extreme-right and fascist views in their music because this gives band members a means of deniability where they can argue that their music is not completely serious. Many Australian metal bands also emphasize patriotism, ferocity, and brutality in the search for some degree of purity within the Australian metal scene (Hoad 2016; Montague 2003). This search for purity within Australian metal is especially ironic given the high degree of genre hybridity within Australian metal (Hoa, 2016; Hillier 2018, 2019b). Since Australian extreme metal does not appear 
to have a single unique sound, but rather is unique in how extensively hybridized it is, the concept of stylistic purity is redundant (Hillier 2018, 2019a, 2019b). The purification being sought by these bands is not one of musical style, but of ideology and the characteristics of others within the scene, which takes on an explicitly racial angle in the context of our case studies. While the explicit political goals of Australian metal bands have not yet been discussed in detail, these constructions of race, Otherness, and Australianness within the Australian extreme metal scene provide the context for the ideological statements of performers and their bands, discussed below.

\section{Extreme right-wing ideologies in Australian black Metal}

Overt fascist views in Australian extreme metal are frequently obstructed with references to the occult, paganism, Norse culture, Satanism, or general misanthropy, as they are in other NSBM scenes (Olsen 2011; Spracklen 2013). Many of these bands do not participate in mainstream music scenes or conventional underground metal scenes in their local area, creating a sub-underground scene, which runs parallel to local metal scenes. Our observations of the Tasmanian metal scene demonstrate that it is rare to see NSBM bands perform at mainstream community venues, due to genre crossovers with punk and metal (Hickam and Wallach 2011; Piper 2013; Kennedy 2018). Rather, gigs are held privately, often in sheds or backyards and on a strictly invite-only basis. Those who may be offended by these bands' political statements at gigs are thus excluded from attendance (Peyper 2018). Information is difficult to find and intentionally obfuscated unless one is already aware of the relevant bands, symbols and dog-whistles used by these groups. For example, one especially puzzling example of coded language in the Australian extreme metal scene is the insistence by some Australian NSBM groups on referring to Tasmania as "Van Diemen's Land", the name used for the state from 1825-1856 (Rattenkönig 2019). The reason for this is not presently clear, though it seems to be a deliberate attempt to ground these groups' sense of place explicitly within Australia's colonial past. Due to the insular nature of neo-Nazi and fascist groups, band members perform in several bands at once and perform together frequently or on neo-fascist music labels (Southern Poverty Law Center 2020). Larger festivals or performances, such as the annual Recrucify the Bastard festival held in Launceston, Tasmania, are comparatively rare. To pinpoint the exact location and timing of these concerts is difficult as they are advertised either through word-of-mouth or online in specific locations. These events rarely advertise explicit political views, instead of appearing as intensely anti-Christian, giving band members deniability for patriotic values and white nationalism (Pollard 2016). This is common for white power music, which promotes social division through music to recruit members with the ultimate goal of creating a transnational white supremacist movement (Love 2016).

Owing to the covert nature of these scenes, we have elected to focus our initial research on more visible bands within Australian extreme metal, though these subunderground scenes remain an important avenue for future research to investigate. Perceiving Australian metal's fascist tendencies typically requires one to closely examine both lyrics and paratexts, which will be the focus of this section. The first case study is based around the band Spear of Longinus, who make extensive and explicit references to Nazism throughout their body of work, and are perhaps the most overt example of fascist and Nazi sentiment within the Australian metal scene 
(Giffin 2015). Though very influential within NSBM scenes locally and internationally, Spear of Longinus is by no means a prominent band within more mainstream metal scenes.

The cover of Spear of Longinus' demo Nazi Occult Metal (1995) invokes several common NSBM tropes (beyond the title). The album cover recalls various NSBM aesthetics, using poorly drawn figures and a colour scheme dominated by black and red. Norse runes are appropriated to spell both the bands' initials on the horizontal sides of the tape (here as S.O.L) and the title "Nazi Occult Metal" on the vertical sides, a common reference in NSBM circles to Aryan heritage and appropriated Norse and neo-pagan religious practices (Olsen 2011). The artwork itself depicts what appears to be a black metal musician, wearing corpsepaint (a type of makeup worn by black metal bands to imitate the sunken features of a corpse), kneeling before a devil figure and offering them a goblet; assumedly, these elements comprise the occult elements of the title. The swirls seen in each corner of the cover resemble swastikas, particularly within the context of them bordering the words "Nazi Occult Metal". The lyrics of the title track feature a middle section that extemporizes Nazi ideology, asserting the supremacy of the German race and concluding with the lyrics "The party is Hitler/Hitler is the party/Germany is Hitler/Hitler, Sieg heil!" (Spear of Longinus 1995). The other songs on the album make extensive reference to Norse mythology, calling upon various Norse gods to aid them in battles and occult rites. Musically, the band conforms to the conventions of war metal, an especially extreme subgenre of black and death metal. Production values are low-fidelity, much of the riffing is based around down-tuned and extremely distorted power chords, alongside constant, pounding drums throughout their songs. One notable difference is present: the vocals are remarkably clear by black and war metal standards such that the lyrics are fairly easily understood.

The second side of Nazi Occult Metal (Spear of Longinus 1995) features a nearidentical copy of the first side, save that the vocal track is doubled by guest vocalist Rurik. Rurik's vocals almost resemble spoken word, rather than the conventional howling, screaming, or growling expected of extreme metal (Smialek, Depalle and Brackett 2012; Purcell 2015). Given the heavily ideological content of the lyrics, this seems a deliberate choice to make the lyrics more intelligible than other examples within their subgenre, allowing the ideological content to be absorbed by the listener more easily. Following from this are Spear of Longinus' albums The Yoga of National Socialism (hereafter TYONS) and ...And the Swastikalotus. These albums make further references to various national socialist ideas in their titles and in their album artwork, demonstrating the ongoing pattern of infusing their political ideologies within their music. For example, the cover of ...And the Swastikalotus (Forgotten Wisdom Productions 2007) continues the simple black-and-red colour scheme seen on the Nazi Occult Metal demo, prominently displaying a Swastika in the upper right of the cover. This illustrates an aesthetic continuity from the earliest, explicit, demos that discuss Nazism to the more recent output that is somewhat more occluded.

Beyond aesthetics, the lyrics of TYONS (Vinland Winds, 2002) introduce elements of Hinduism and Buddhism. This album draws heavily from stories and symbolism of Shiva, Vishnu and Buddha in addition to the references to Norse mythology. This appears to be an attempt to fuse a sense of occult spiritualism and a fascist political ideology (represented by the allusions to Nazism and white nationalism) into one entity that the band refer to as "Gnostic Nazism" ("Joe" 2003; 
Carr 1998). This "Gnostic Nazism" encompasses the full artistic vision of the band, who suggest that their combination of fascism and esoteric mythology as a lyrical theme was unique in Australian metal when they began (Carr 1998). The esoteric nature of their lyrics allows them to draw on more cryptic elements of Nazism, with references to the Black Sun on the collection of EPs Black Sun Society (Vinland Winds 2004). "The Black Sun" was used by the Nazis to represent divine salvation, an alternative for the swastika, carrying occult and Satanist connotations. (Goodrick-Clarke 2003). This collection includes the song "World of Shit" which references Nietzsche's Thus Spake Zarathustra (1950) and concludes with the lines "The World has never sunk so low/Rome sank to whoredom and became a stew/ The Caesars became beasts/ And God a Jew" (Vinland Winds 2004). McWilliams (2014) and Spracklen (2010) both note that there has been a consistent tension between musical expression and elitist ideology in black metal music. This manifests as a misunderstanding of many aspects of Nietzsche's philosophy and Spear of Longinus' references to Nietzschean ideas should be understood within this context. These examples are significant, as they illustrate that the overt Nazism and fascist sentiments of Nazi Occult Metal (Spear of Longinus 1995) were not a one-time idea which was explored in a demo recording and then discarded; rather, they permeate the band's entire body of work, hidden within layers of symbology, esoterica, or otherwise coded language.

The second case study is focused on the work of Deströyer 666. Though based in Europe since 2001, Deströyer 666 nonetheless originated from and are closely identified with the Australian extreme metal scene, and are regarded as one of the most prominent Australian extreme metal bands (Giffin 2015). While not as overt with their fascist leanings as Spear of Longinus, several racist, nationalist, and sexist sentiments pervade both their textual and paratextual content. Notably, front man K.K. Warslut has faced several controversies for his conduct and comments at Deströyer 666 live performances. A performance in Denmark in 2016 prompted a public feud with magazine Metalsucks and their tour of Australia and New Zealand in 2019 was cancelled when their tour dates were protested. Protests arose following several magazines drawing links between the ideology professed by Deströyer 666 and that of the Christchurch Mosque Shooter (Hohen 2019; Mckenzie-King 2019)(2). In contrast to Spear of Longinus, Warslut consistently and vehemently denies that he holds or professes any views that could be considered racist, sexist, homophobic, or otherwise problematic, often immediately after detailing these views during an interview (Kristiansen 2015; Göransson 2016). A full detailing of the many controversial statements made by Warslut is beyond the scope of this paper; accordingly, we will concentrate on an analysis of select song lyrics and album covers presented by the band and how these relate to statements made by Warslut, including a particularly infamous speech at a music festival. We now turn to Deströyer 666's album, Unchain The Wolves (Modern Invasion Music, 1997).

The artwork on this album is especially significant to understanding the ideology advocated by KK Warslut via his work in Deströyer 666. It depicts a large white wolf baring its teeth and standing over the corpse of a smaller brown wolf, which has troubling implications in the context of how wolves are used by the band. Wolves are a common theme in the artwork and lyrics of Deströyer 666. Warslut has stated in an interview that the wolf on this cover represents "the spirit of the white man" (Alternative Underground 2014; "@ndy", 2016; Hohen 2019)(3). Given 
the content of the album cover, it is difficult to see how else one could interpret this album cover apart from a statement of white supremacy. In the lyrics of the album, wolves are mentioned frequently, where the wolf is emblematic of white Europeans, set against both Christianity and an unknown "them" (see "Genesis to Genocide"). It is unclear who exactly "them" refers to, but Deströyer 666 are specific when it comes to opposing Christianity.

Notably, the lyrics throughout this album refer to a distinctly European identity in their protagonist that is set against a Christian enemy. For example, the song "Australian and Anti-Christ" is reasonably straightforward, though it contains the puzzling couplet "Don't wanna be chained to your cross/I'm not ashamed of being white". The link between being chained to Christianity and feelings of pressure to be ashamed of one's whiteness is apparent but the reasons that this link should cause these feelings is unclear. "Unchain The Wolves" states: "the scourge of the cross... took the occult magic of the white man" and that "unchaining the wolves" is to set them free against the oppressive nature of Christianity. While Christian churches were certainly involved in the invasion and colonisation of Australia, it was not white people that they were targeting as organized religion was brought to Australia by British colonial forces. Indeed, many Christian organizations directly aimed to subjugate Indigenous Australians and participated in the systematic eradication of their culture and spirituality through forced assimilation on church missions (see Moses 2000). Deströyer 666's presentation of Christianity is thus an interesting sense of victimization that is prominent in anti-Christian rhetoric derived from a sense of lost pagan European culture within European black metal scenes (Olsen 2011). The band do not see their origins in Australia as presenting a problem for this reading; for Deströyer 666, being Australian inherently means to be white and to have European heritage. This is evident in an interview with Slayer magazine, where Warslut explains that the Australianness in "Australian and AntiChrist" means to be a product of the British Empire and white Europeans (Kristiansen 2015). There is a bitter irony to this view; for a band that rails against the Christian destruction of pagan European culture, it is concerning that they simultaneously celebrate the exact same cultural destruction being done to Indigenous Australians following the British invasion.

These two case studies illustrate how the paratextual elements of both Deströyer 666 and Spear of Longinus advocate for far-right and fascist views in their music, through both texts and paratexts. They illustrate that these views are not just present in a marginalized, underground NSBM band like Spear of Longinus, but also in a prominent, world-touring band like Deströyer 666. In these cases, black metal music is clearly being used as a vehicle to advocate nationalist, extreme-right, and fascist ideologies. In the following sections, we wish to respond to common counter-arguments made within metal communities to defend, mitigate, or otherwise exonerate bands who express problematic (or outright fascistic) ideologies in order to maintain the acceptableness of these bands within the wider scene.

\section{Apolitical fascism: Reflexive anti-reflexivity and genre}

The first defence often made by extreme metal bands with problematic politics is to designate themselves as being apolitical, regardless of statements that they have made which are deliberately political. Ideas of reflexive, unreflexive, and anti- 
reflexive practices are integral to understanding how these designations operate in metal scenes. Social theorists typically conceptualize reflexivity as a set of routine behaviours which are incorporated into a person's characteristics and conduct, a type of self-monitoring that is rooted in expectations of others (Bourdieu1990; Giddens 1984). The concept of reflexivity, as explained by Bourdieu (1990), posited that social scientists needed to be aware of their position within their study and how their behaviours, language, and interpretation assists in relatability with others when investigating a social space (Bourdieu and Wacquant 1992; Gingras 2010; Mullany 2013). Following this, Keith Kahn-Harris (2007) developed the concept of "reflexive anti-reflexivity" to describe how the way in which those in metal scenes conceptualize their reflective practice is deliberate. Reflexive anti-reflexivity is "knowing better but deciding not to know", in contrast with practices that are either unreflexive (not knowing better) or anti-reflexive (not wanting to know), both of which are rare within metal (Kahn-Harris 2007: 145). In practice, this may appear as problematic statements from bands (be they fascist, racist, sexist, homophobic, etc.) being construed as humour, satire, or otherwise insincere (Kahn-Harris 2007: 151-3; Wendel 2002). This humour is routinely used to minimize the significance of harmful material and its purpose to perpetuate social inequalities (McDiarmid et al. 2017).

Drawing from this, reflexive anti-reflexivity suggests that scene members who engage in problematic behaviour are doing so by choice. They are not simply being unreflexive but are instead choosing not to be reflexive in how their opinions and actions affect others. Thus, their statements are communally being recognized as being problematic but rather than modifying or disavowing them, bands and fans choose to seek ways to excuse their problematic nature (see Strong and Rush, 2018). Reflexive anti-reflexivity requires some recognition that these statements are indeed problematic, otherwise there would be no attempt at all to mitigate their reception.

This reflexive anti-reflexivity manifests in several ways within the context of the Australian black metal bands. For example, the Facebook page of Spear of Longinus contains the disclaimer that "Spear Of Longinus is not politically or racially motivated" (Spear of Longinus 2020). In effect, Spear of Longinus are attempting to construe themselves as somehow being apolitical while explicitly, deliberately, and intentionally advocating fascist views in their music. We interpret this statement to act as a token disclaimer to provide the band with deniability should they be accused of violating the Terms of Service of a platform like Facebook. Given the band's explicit support of and involvement with political groups which have neoNazi goals and sympathies, the political motivations of the band are undeniable. This is reinforced when the band themselves do not make serious attempts to explain their explicit membership to fascist organisations (Carr 1998; "Joe" 2003; Völker 2016). Thus, this is a reflexively anti-reflexive practice; the statement that Spear of Longinus is not politically or racially motivated only exists as a mitigation of their political views, suggesting that there is some level of recognition that they are problematic yet continue to expound these views in their music and interviews.

The second manifestation of reflexive anti-reflexivity within Spear of Longinus' body of work suggests that the elements of Gnostic Nazism are satirical or otherwise non-serious. This includes not taking themselves too seriously, an idea seemingly supported by song titles like "YHWH Penis Abominator" from ...And The Swastikalotus (Forgotten Wisdom Productions 2007). Satire, in this sense, is when a band is attempting to be more extreme and transgressive than their competitors, 
using humour to demonstrate the inversion of traditional morals and values upheld by society (Hay 2016; Vestergaard 2016; Unger 2016). Similarly, it is not uncommon for bands with extreme music styles to appear more radically minded than they are, such as in the case of appropriating Nazi symbolism for shock value, where wearing a swastika is either a symbol for shock value or a sign through which to incite hate against the wearer, a symbol of menace and disdain (McNeal and McCain 1996; Ward 1996). Spear of Longinus' usage of "Gnostic Nazism" might thus be justified as an expression of this style of extremity, with the more humorous songs serving as an indicator of the band's true intentions. In this way, understanding the larrikin identity within Australian extreme metal as the only or dominant identity is problematic, as it provides further deniability to bands like Spear of Longinus within this context.

However, the use of satire and humour is easily dispelled when paired with the explicit views of band members themselves. Spear of Longinus for example, have been noted in interviews to state that they explicitly adhere to and advocate for fascist and national socialist viewpoints via their music (Völker 2016; "Joe" 2003). This removes the possibility that these elements are intended to be satire. Even without explicit interviews, this ideology pervades both the paratexts and the texts of Spear of Longinus to such a degree that the satire argument is already extremely implausible. Secondly, even if these ideas were intended to be a joke, this would still not excuse such unreflexive practices; reflexivity in music is essential due to the impact of lyrics, language and symbolism. The use of language (whether this be sexist or fascist jokes), does not passively reflect the current social reality, but is an active agent in constructing that reality (Christie 2002).

Furthering this, these bands are not only choosing not to be reflexive, but they are being strategic about it. For example, in an interview, Warslut responds to several criticisms of his political opinions throughout his career, alleging that his band does not contain racist, nationalist, sexist, or otherwise problematic sentiments or content (Göransson 2016). While we have shown in this paper that one can indeed find many examples of these sentiments in the work of Deströyer 666, it is worth examining how exactly Warslut uses reflexively anti-reflexive practices to defend his own art. One example is seen in how Warslut responds to criticism of the cover of Deströyer 666's EP Of Wolves Women And War (Satans Metal Records 2002), which features a werewolf sodomizing a naked woman who closely resembles Australian singer Kylie Minogue. There is a range of problematic elements present on this cover, although we will focus on two. One is the issue of consent, as we doubt Kylie Minogue endorsed her likeness being used in the context of this album cover, as no mention is made of it in the liner notes and the cover puts her into an explicitly sexualized position; given these dubious issues of consent, we have elected not to include an image of this cover in this paper but instead describe the image sufficiently to explain our point. Secondly, given the previous context in which wolves have been used by Deströyer 666 to represent "the spirit of the white man", this cover appears to be communicating that the white man as a wolf exists to sexually dominate women. Warslut defends this cover by arguing that such an act of "lycanthropic buggery" would not be endorsed by Adolf Hitler (Göransson 2016). Warslut argues that such "degeneracy" (itself a dog whistle used by fascist groups) would not be approved by the Nazis, therefore he and his band cannot be expressing Nazi sentiments at all in their work (Göransson 2016). This illustrates how Warslut is attempting to construct political criticisms of his art - either the art advocates something that Hitler himself would approve of, or it 
cannot express Nazi sentiments. Obviously, this dichotomy is absurd and largely irrelevant to the content of the cover itself, but it illustrates the extremes that reflexive anti-reflexivity can be taken to, even if the argument itself is incoherent.

Warslut also specifically denies many accusations that Deströyer 666 is a racist band due to the absence of racist song lyrics (Göransson 2016). We have illustrated in this paper that racist and white supremacist sentiments pervade the lyrics of Deströyer 666, yet beyond this there are several extra-musical examples of racist ideology being expressed within the context of Deströyer 666's work. There is recorded footage of Warslut in 2012 at Deathkult Open Air Festival yelling to the crowd:

This one is for all the Muslim immigrants who are invading - who are invited to invade our fucking continent: fuck you Allah! Yeah, everyone's busy being anti-Christian. Fuck being anti-Christian, let's be fucking anti-Muslim for once! This is our fucking land! (Warslut, in GronSS 2012)

Deströyer 666 then launch into a song titled "Raped". These comments made by Warslut are deeply Islamophobic and racist. Whilst Warslut claims that Deströyer 666 are not a racist band because their lyrics do not contain overtly racist sentiments, these statements contextualize those lyrics. Fans are expected to either completely ignore a specific instruction to be anti-Muslim made by Warslut himself, at a live show, or to consider these statements as not being inherently racist or discriminatory. These comments are not only a demonstration of how Deströyer 666 are strategically choosing to be reflexive but also how they fabricate their fanbase's political consciousness.

In this section, we have illustrated how reflexive anti-reflexive practices function as an attempt to excuse the usage of aesthetic elements that might be considered problematic. These range from those that overtly draw on Nazi iconography (such as Spear of Longinus' album covers), to those that are problematic in other ways (such as Deströyer 666's album covers). We have also shown how these arguments fail when interrogated. In many ways this is concerning: the arguments deployed by these bands to excuse their extreme ideologies are so thin that they collapse with only the smallest interrogation, and are clearly only being accepted by fans so that they are not required to surrender music that they otherwise enjoy.

\section{How it all comes together: Black Metal, ideology, and Gesamtkunstwerk}

We have demonstrated the way in which certain metal bands can push fascist views and simultaneously deny their reality or consequences by separating their art from themselves via reflexive anti-reflexive practices. However, this separation of art and ideology, in fact, misunderstands one of the fundamental ways that black metal differentiates itself from other metal subgenres. In order to explain this, we will explore a framework that understands black metal to function as a "Gesamtkunstwerk".

"Gesamtkunstwerk", meaning "total work of art", is a theory of art made famous by composer Richard Wagner, who used the term to describe his "music drama" as a genre that combined a range of different media alongside rhetoric into a single art form (Millington, 2002). Within the context of black metal, Gestamtskunstwerk 
takes on a different implication. As Lesourd (2013) argues, black metal should be considered its own aesthetic category: more than a genre of music, it is a complete form of artistic and aesthetic expression, requiring musicians and artists to be inseparable from their creations. It is specifically black metal's expression of aesthetics and ideology through lyrics and album covers that requires black metal to be conceived as a Gesamtkunstwerk to the point that the genre's ideology differentiates black metal from other subgenres of metal (Smialek 2015). The aesthetic and extra-musical elements are integral to metal genre definitions and the ideological elements of black metal are integral to its coherence as a genre. Notably, this understanding of black metal reflects how the origins of the label were used for any metal music which had explicit links to Satanic themes, regardless of musical style, though the current use of the label does encompass a discrete musical style (Hillier 2020; Christie 2003; Smialek 2015). The significance of the Gesamtkunstwerk framework is in its redefinition of the text-paratext relationship. While one can argue that problematic material in the paratext influences one's reading of the main text (as we have illustrated earlier), black metal's inclusion of the artists' philosophies as a means to fully engage with the text draws these beliefs out of the realm of paratext and into the text itself. Thus, one cannot separate the art from the artist as the persona and beliefs of the artist are made a part of the text itself and therefore surface and become real. Each of these factors supports the framework of a Gesamtkunstwerk being one that is appropriate for black metal, and one that reflects how the genre is understood in the academic literature and in fan discourse.

Furthermore, the framework of black-metal-as-Gesamtkunstwerk suggests that the extra-musical and paratextual elements of black metal cannot be separated from either their creators or the artwork itself; therefore, the creators are inseparable from their art. Here, we return to K.K. Warslut's defence of his Islamophobic speech and the lyrics of Deströyer 666. Evidently, a black metal band cannot separate the dangerous political views expressed by an individual within the band from the art created by the collective. To do so would be to contradict how black metal has always operated and continues to operate, with the ideology of the artist as an integral part of its identity as a musical genre, especially if that ideology is transgressive. This defence exposes an inherent contradiction at the very heart of black metal.

One argument suggests that these problematic political views are a core part of the genre and cannot be disregarded when inconvenient or uncomfortable. Another contradiction is the suggestion that political ideology holds no importance to the genre at all. This is not accurate, as there have been a huge range of ideologically motivated black metal bands since the genre's inception. For example, the Norwegian black metal scene solidified itself around strong anti-Christian sentiments that resulted in a series of arsons and church burnings (Moynihan and Søderlind 2003; Johnson and Cloonan 2009). As with reflexive anti-reflexivity, there is some awareness that this stance is contradictory. In this case, the categorisation of NSBM as a separate scene and subgenre relative to normal black metal scenes suggests that the most problematic and overtly fascist bands are understood to some degree as 'not us' by non-NSBM black metal bands and fans. In practice, however, we observed that many musicians who operate within the normal black metal scenes have little issue with collaborating with band members who participate in NSBM or similar scenes. Additionally, Deströyer 666 illustrate that bands who are prominent members of more visible extreme metal scenes can 
be just as problematic regarding the politics and ideologies that they advocate as those engaged in the sub-underground scenes.

\section{Fan responses: Theory into praxis}

It is important to move beyond a philosophical discussion of the art, ideologies, and rhetoric presented by Australian black metal musicians and to examine how these views are transferred to fans. The views of KK Warslut, as expressed through Deströyer 666, are contextualized by fans of the band, shown in Figure 1.

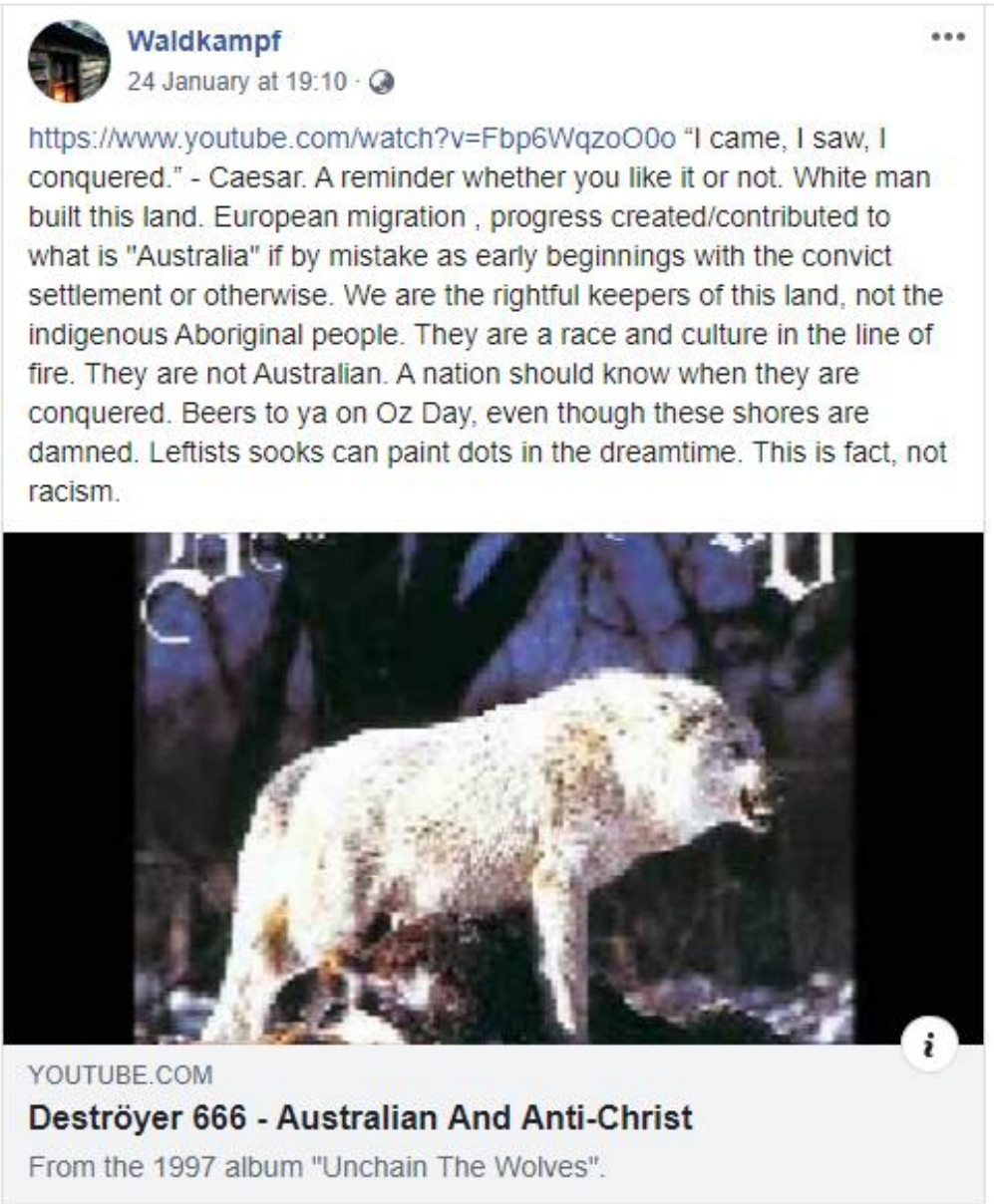

FIGURE 1. Facebook post from Waldkampf featuring link to Deströyer 666's "Australian and Anti-Christ".

In relation to the debate around holding the Australia Day holiday on January $26^{\text {th }}$, Waldkampf belittles the culture and current status of Indigenous Australians while recontextualizing the British invasion of Australian as cultural progress(4). This statement is explicitly linked to the aforementioned Deströyer 666 song "Australian and Anti-Christ". This illustrates that our white supremacist reading of these lyrics is not subtext or an unconventional reading; even fans of the band interpret and use their lyrics this way. Thus, it would appear that putting Deströyer 666's lyrics in an explicitly political context is only upsetting for the band and their fans when that political context is one that they dislike. "Australian and Anti-Christ" is being used by Waldkampf to categorize Indigenous Australians as not Australian and to argue that "white man" alone built Australian society. They also specifically 
align themselves against "leftist sooks", who they construct as being the only people who care about Indigenous Australian culture (here reductively described as "painting dots in the dreamtime"). These actions are concerning; for all the arguments over how ideology in metal is to be understood, for all the reflexively anti-reflexive practices being used as token deniability, the proof of the danger of extreme-right ideologies is seen in the actions taken by fans. In effect, it does not matter whether or not Deströyer 666 are actually advocating for nationalist, extreme-right views or just pretending to - their fans clearly think that they are and perceive it as appropriate to use their music within a nationalistic, white supremacist context. If the wider metal communities allow this behaviour to continue unchecked, this behaviour will only become bolder and more explicit.

A different response is possible. An international Red and Anarchist Black Metal (hereafter RABM) movement is steadily growing, following coverage of some of the more prominent bands gaining news attention, including a congregation of likeminded black metal musicians in dedicated RABM forums (Kelly 2018). Many of these bands are explicitly critical of the current international black metal scene, with bands such as Gaylord and Neckbeard Deathcamp releasing albums respectively titled The Black Metal Scene Needs to Be Destroyed (2018) and White Nationalism is for Basement-Dwelling Losers (2018). Other bands who operate within more mainstream or conventionally underground extreme metal scenes such as Iskra, Panopticon, and Dawn Ray'd are also associated with the movement (Kelly 2018). The authors have not observed any specific movement in Australian extreme metal scenes, but bands like Dispossessed are known to perform with a specifically anti-colonial, anti-racist, and anti-fascist platform (Dispossessed 2020). The RABM movement is significant as it represents a progression away from reflexive antireflexivity toward a reflexive self-regulation of the extreme metal scene that recognizes and rejects problematic and extreme political views. This movement recognizes that ideology forms a significant part of the black metal genre identity and instead, seeks to redefine it away from extreme right-wing politics. The characteristic aesthetic, musical, and lyrical aggression of black metal is present within many of the RABM bands and attempts at reclaiming symbols appropriated by NSBM bans (such as references to Norse Mythology) can be seen in songs such as "Odin Doesn't Listen to NSBM You Inbred Alt-right Shitheels" (Gaylord 2018). As such, RABM offers an ideological alternative for a fan who might enjoy the musical stylings and aesthetics of the sub-underground NSBM bands while specifically criticizing these scenes. While it is unlikely that far-right politics and NSBM will ever be completely removed from extreme metal, these are important steps in ensuring that fascist ideology within the scene is recognized and dealt with accordingly while developing a sense of social control and self-regulation within the scene.

\section{Conclusion}

We have illustrated the prevalence of fascist sentiment within the Australian black metal scene, both historically and within the current Australian discourse. Although it has been suggested that NSBM would likely remain a marginal phenomenon (Olson 2011), we have shown that this not currently the case. We have illustrated how Australian black metal bands employ practices that are reflexively antireflexive in order to mitigate or otherwise render these ideologies as nonproblematic. We then examined how many of these practices are flawed within 
black metal owing to its self-conception as a Gesamtkunstwerk and thus they must be engaged with one way or another.

There are several avenues for future research in light of this paper. One avenue is to contrast Australian metal with other subgenres of extreme music in Australia (such as punk) to understand how and why they differ when responding to extremeright ideologies. Further work is needed to examine in detail the origins of rockbased genres within Australia to determine why genres with similar points of origin (i.e. the Australian pub rock scene in the 1970s) developed such wildly divergent ideological frameworks; and the exact role that international respective genres played in this development. Given the specific white supremacist nature of NSBM, a musicological examination of the interactions between extreme metal and heavy metal's differing approaches to non-white musical influences presents a significant avenue for future study noting that many extreme metal subgenres have removed blues musical features from their music. Other research might examine how the sub-underground scenes identified in this paper function, the mechanisms of their operation as music scenes, and how the members within these scenes relate to conventional underground extreme metal scenes in Australia more specifically.

\section{Endnotes}

(1) 'Yobbo' is a slang word in Australian English to describe someone commonly of a working-class background who is generally regarded as uncouth and coarse. While yobbo is mainly applied to (young) men, the similar term bogan is applied to both genders and is also commonly associated with Australian stereotypes in Australian metal.

(2) The Christchurch Mosque Shooter (Brenton Tarrant), a 28-year-old Australian with no previous criminal history who was active on extreme-right internet forums, entered the $\mathrm{Al}$ Noor mosque in Christchurch, New Zealand, where he allegedly shot dead 50 people and injured 48 (Besley and Peters, 2020; Macklin, 2019).

(3) In between the researching and final writing of this paper, the online copy of this interview was deleted from YouTube and is no longer available to be viewed. Several sources that linked to this interview (Alternative Underground, 2014; "@ndy", 2016; Hohen, 2019) mention the specific comment about "the spirit of the white man" and the authors can confirm that they have heard this interview and attest that this comment was made by Warslut. The original source appears to be the 2014 blog post on Alternative Underground, which also provides a transcript of some additional comments made by Warslut and records the blog writer's interpretations of the interviewer's reactions to Warslut's statements.

(4) The celebration of Australia Day on January 26th has long been controversial, though there has been increasing public awareness and discussion of the date in recent years (Morgan, 2019). January 26th commemorates the official declaration of British sovereignty in Australia in 1788 (though it is commonly and incorrectly thought to mark the arrival of the First Fleet in Sydney Cove) and has been Federally recognized as a public holiday in Australian since 1994. For Indigenous Australians, in particular, this date represents a commemoration of British invasion, and is sometimes referred to as Invasion Day, with formal protests conducted on that date since 1988 (Morgan, 2019). 


\section{References}

\section{Bibliography}

Besley, T. and Peters, M.A. 2020. Terrorism, Trauma, Tolerance: Bearing Witness to White Supremacist Attack on Muslims in Christchurch, New Zealand. Educational Philosophy and Theory 52 (2): 109-119.

Bourdieu, P. 1990. In Other Words: Essays Towards a Reflexive Sociology. California: Stanford University Press.

Bourdieu, P. \& Wacquant, L. J. 1992. An Invitation to Reflexive Sociology. Chicago: University of Chicago Press.

Carr, B. 1998. BLITZKRIEG!!!!. Quiddity Zine [online]. 2, http://quiddityzine.tripod.com/spearof.htm, accessed 17 February 2020.

Cotter, J. M. 1999. Sounds of hate: White power rock and roll and the neo-nazi skinhead subculture. Terrorism and Political Violence 11: 111-140.

Christie, F. 2002. Classroom Discourse Analysis: A Functional Perspective. London: Continuum.

Clarke, M.A. 1979. Reading in Spanish and English: Evidence from ESL tests. Language Learning 29: 121-150.

Christie, I. 2003. Sound of the Beast: The Complete Headbanging History of Heavy Metal. New York: Harper Entertainment.

Driver, C. 2016. "Bringing the Vibe": Subcultural Capital and "Hardcore" Masculinity. In S. Baker, B. Robards and B. Buttigieg Eds. Youth Cultures and Subcultures: Australian Perspectives. Farham: Ashgate: 193-204.

Ensminger, D. A. 2011. Visual Vitriol: The Street Art and Subcultures of the Punk and Hardcore Generation. Jackson: University Press of Mississippi.

Giddens, A. 1984. The Constitution of Society: Outline of the Theory of Structuration. California: University of California Press.

Giffin, B. 2015. Encyclopedia of Australian Heavy Metal. Katoomba: Dark Star.

Griffin, N. 2012. Gendered performance: Performing Gender in the DIY Punk and Hardcore Music Scene. Journal of International Women's Studies 12 (2): 66-81.

Gingras, Y. 2010. Review Essay: Sociological Reflexivity in Action: Pierre Bourdieu, Sketch for a Self-analysis. Social Studies of Science 40: 619-631.

Hannon, S. M. 2010. Punks: A Guide to an American Subculture. Westport: Greenwood Press.

Hamm, M. S. 1993. American Skinheads: The Criminology and Control of Hate Crime. London: Greenwood Publishing Group.

Hamm, M. S. \& Spaaij, R. 2017. The Age of Lone Wolf Terrorism. New York: Columbia University Press.

Hay, A. 2016. Cruelty Brought Thee Orchids (and Irony) - The Covert Social Satire of Cradle of Filth. Metal Music Studies 2(1): 125-134.

Haney-López, I. 2015. Dog Whistle Politics: How Coded Racial Appeals have Reinvented Racism and Wrecked the Middle Class. Oxford: Oxford University Press.

Hickam, B. \& Wallach, J. 2011. Female Authority and Dominion: Discourse and Distinctions of Heavy Metal Scholarship. Journal for cultural research 15: 255277. 
Hillier, B. -

2018. Investigating the Australian Sound in Australian Extreme Metal: A Review of the Literature. Through the Looking Glass: 41 st Musicological Society of Australia National Conference, 2018. Perth, Western Australia, 5-8 December 2018. Musicological Society of Australia.

2019a. Austral Aliens: Australian Identity in Australian Extreme Metal as Expressed Through Visual Paratexts. Belonging and Detachment:

Representing Musical Identity in Visual Culture. 13-15 November 2019, Hobart, Tasmania. Association Repertoire International d'Iconographie Musicale.

2019b. Genre Hybridity in Australian Extreme Metal. 42nd MSA National Conference "Conflict-/-Collaboration". 5-7 December 2019, Monash University, Melbourne.

2020. Considering Genre in Metal Music. Metal Music Studies 6(1): 5-26. Hoad, C. -

2016. Whiteness With(out) Borders: Translocal Narratives of Whiteness in Heavy Metal Scenes in Norway, South Africa and Australia. MEDIANZ: Media Studies Journal of Aotearoa New Zealand 15(1): 17-34.

2019. Critical Introduction: What is "Australian" about Australian Heavy Metal? In: Hoad, C. Ed. Australian Metal Music: Identities, Scenes, and Cultures. Bingley, UK: Emerald Publishing Limited, 1 - 18.

Hohen, M. 2019. Are We Really Touring Destroyer 666 in Australia? Really? Tone Deaf. 23 April https://tonedeaf.thebrag.com/are-we-really-touring-destroyer666-australia/. Accessed: 17 February 2020.

Johnson, B. \& Cloonan, M. 2009. Dark Side of the Tune: Popular Music and Violence. Surrey: Ashgate.

Kahn-Harris, K. 2007. Extreme Metal: Music and Culture on the Edge. Oxford: Berg.

Kelly, K. 2018. Riding the New Wave of Anti-Fascist Black Metal. Vice. 24 August 2018 https://www.vice.com/en au/article/ywkj8y/riding-the-new-wave-of-antifascist-black-metal. Accessed: 17 February 2020.

Kennedy, L. 2018. Functions of Genre in Metal and Hardcore Music. PhD. University of Hull, England.

Kristiansen, J. 2015. Metallion: The Slayer Mag Diaries. New York: Bazillion Points.

Lesourd, E. 2013. Baptism or Death: Black Metal in Contemporary Art, Birth of a New Aesthetic Category. Helvete: A Journal of Black Metal Theory 1: 29-43.

Love, N. S. 2016. Trendy Fascism: White Power Music and the Future of Democracy. Albany: SUNY Press.

Macklin, G. 2019. The Christchurch Attacks: Livestream Terror in the Viral Video Age. CTC Sentinel, 12(6).

McNeil, L. \& McCain, G. 1996. Please Kill Me: The Uncensored Oral History of Punk. New York: Grove Press.

McDiarmid, E., Gill, P. R., McLachlan, A. \& Ali, L. 2017. "That Whole Macho Male Persona Thing": The Role of Insults in Young Australian Male Friendships. Psychology of Men \& Masculinity 18(4), 352-360.

McWilliams, J. 2015. Dark epistemology: An assessment of philosophical trends in the black metal music of Mayhem. Metal Music Studies.1(1), 25-38. 
Millington, B. 2002. Gesamtkunstwerk. Grove Music Online.

https://www.oxfordmusiconline.com/grovemusic/view/10.1093/gmo/9781561592 630.001.0001/omo-9781561592630-e-5000011027. Accessed: 19 August 2020.

Montague, E. 2003. Skill, Music, and Energy in Punk Performance. In Gyde, A. S. Ed. IASPM International Conference. Montreal, Canada.

Morgan, M. 2019. Why Australia Day is Really Held on 26 January and the Push to Change the Date. SBSNews. https://www.sbs.com.au/news/why-australiaday-is-really-held-on-26-january-and-the-push-to-change-the-date. Accessed: 17 February 2020.

Moses, A.D. 2000. An Antipodean Genocide? The Origins of the Genocidal Moment in the Colonization of Australia. Journal of Genocide Research 2(1): 89-106.

Moynihan, M. \& Søderlind, D. 2003. Lords of Chaos: The Bloody Rise of the Satanic Metal Underground. Los Angeles: Feral House.

Mullany, L. 2013. Discourse, Gender and Professional Communication. In Gee, J. P., and Handford, M. Eds. The Routledge Handbook of Discourse Analysis. London: Routledge, 509 - 522.

Olson, B. H. 2011. Voice of Our Blood: National Socialist Discourses in Black Metal. Popular Music History 6: 135-49.

Overell, R. 2015. Brutal Belonging in Other Spaces: Grindcore Touring in Melbourne and Osaka. In Baker, S., Buttigieg, M.B. and Robards, B. Eds. Youth Cultures and Subcultures: Australian Perspectives. Farnham: Ashgate: 89-100.

Piper, J. 2013. Locating Experiential Richness in Doom Metal. PhD. University of California San Diego.

Phillipov, M. 2008. Metal "Downunderground": Mapping the Terrain of the "Great Southern Wasteland". In Mitchell, T. and Homan, S. Eds. Sounds of Then, Sounds of Now: Popular Music in Australia. Hobart, Tasmania: ACYS Publishing, $215-230$.

Pollard, J. 2016. Skinhead Culture: The Ideologies, Mythologies, Religions and Conspiracy Theories of Racist Skinheads. Patterns of Prejudice 50: 398-419.

Potter, P. M. 2005. What is "Nazi Music"? The Musical Quarterly 88: 428-455.

Purcell, N. J. 2015. Death Metal Music: The Passion and Politics of a Subculture. Jefferson: McFarland.

Schilt, K. 2014. The Punk White Privilege Scene: Riot Grrrl, White Privilege, and Zines. In: Reger, J. Ed. Different Wavelengths. 1 st ed. New York: Routledge.

Southern Poverty Law Center (2020). Hate Music, 39 - 56. https://www.splcenter.org/fighting-hate/extremist-files/ideology/hate-music. Accessed: 17 February 2020.

Smialek, E. 2015. Genre and Expression in Extreme Meal Music ca 1990-2015. PhD. McGill University.

Smialek, E., Depalle, P. and Brackett, D. 2012. A Spectrographic Analysis of Vocal Techniques in Extreme Metal for Musicological Analysis. ICMC, NonCochlear Sound, Ljubliana, 9-14 September.

Spracklen, K. -

2010. True Aryan Black Metal: The Meaning of Leisure, Belonging and the Construction of Whiteness in Black Metal Music. Critical Issues: The Metal Void 1: 81-93. 
2013. Nazi Punks Folk Off: Leisure, Nationalism, Cultural Identity and the

Consumption of Metal and Folk Music. Leisure Studies 32: 415-428.

Strong, C. and Rush, E. 2018. Musical Genius and/or Nasty Piece of Work?

Dealing with Violence and Sexual Assault in Accounts of Popular Music's Past.

Continuum 32(5): 569-580.

Thornton, S. 1996. Club Cultures: Music, Media, and Subcultural Capital. Middletown: Wesleyan University Press.

Threadgold, S. 2015. (Sub) Cultural capital, DIY Careers and Transferability: Towards Maintaining "Reproduction" when Using Bourdieu in Youth Culture Research. In Baker, S. and Robards, B. Eds. Youth Cultures and Subcultures: Australian Perspectives. Farnham: Ashgate: 53-63.

Unger, M. 2015. Sound, Symbol, Sociality: The Aesthetic Experience of Extreme Metal Music. New York: Springer.

Vallen, S. 2019. "A Blaze in the Northern Suburbs": Australian Extreme Metal's Larrikinish Lineage. In: Hoad, C. Ed. Australian Metal Music: Identities, Scenes, and Cultures. Bingley: Emerald Publishing Limited, 37-53

Vestergaard, V. 2016. Blackletter Logotypes and Metal Music. Metal Music Studies 2(1): 109-124.

Wendel, W. B. 2002. Mixed Signals: Rational-Choice Theories of Social Norms and the Pragmatics of Explanation. Indiana Law Journal 77(1): 1-62

Whiting, S., Klimentou, P. and Rogers, I. 2019. "We're Just Normal Dudes": Hegemonic Masculinity, Australian Identity, and Parkway Drive. In Hoad, C. Ed. Australian Metal Music: Identities, Scenes, and Cultures. Bingley: Emerald Publishing Limited, 55-70.

\section{Web Sources}

"@ndy". 2016. Deströyer 666 Australian Tour (November 2016) https://slackbastard.anarchobase.com/?p=40403. Accessed: 17 February 2020.

Alternative Underground. 2014. Destroyer 666: "Spirit of the white man." Colourful comments during a radio interview. https://alternativeandundergroundmusic.blogspot.com/2014/03/. Accessed: 17 February 2020.

Dispossessed. 2020. Dispossessed - about. https://www.facebook.com/DISPOSSESSEDPEOPLE/about/?ref=page_internal. Accessed: 17 February 2020.

Göransson, N. 2016. Destroyer 666. Bardo Methodology. 27 July http://www.bardomethodology.com/articles/2016/07/27/destroyer-666interview/. Accessed: 17 February 2020.

"Joe". 2003. Interview: Camazotz and Paraplethon (Spear of Longinus). Death Metal Underground. http://www.deathmetal.org/interview/camazotz-andparaplethon-spear-of-longinus/. Accessed: 17 February 2020.

McKenzie-King, M. 2019. Keep Destroyer 666 from touring Australia. Megaphone.org. https://www.megaphone.org.au/petitions/keep-destroyer-666from-touring-australia. Accessed: 19 August 2020.

Spear of Longinus 2020. Spear of Longinus - about. Facebook page. Accessed 17 February 2020. 
Völker, G. 2016. SPEAR OF LONGINUS interview. Ukonvasama, 1 [online] http://veriyhteys.com/this-is-the-original-english-version-of-exclusive/, Accessed: 17 February 2020.

\section{Discography}

88, Moloch, \& Iron Youth 88. 2008. Unsere Krieg ("Our War"). Acclaim Records/Ancient Legacy Productions, ID: AR021/ALP005.

Bathory. 1987. Under the Sign of the Black Mark. Under One Flag, ID: FLAG11, Stockholm, Sweden.

Deströyer 666 1997. Unchain the Wolves. Modern Invasion Music, ID: MIM 7325-2 CD, Adelaide, Australia. 2002. Of Wolves, Women and War. Satans Metal Records, ID: SM 001, IJmuiden, Holland.

Gaylord. 2018. The Black Metal Scene Needs To Be Destroyed. Independent. Neckbeard Deathcamp. 2018. White Nationalism is for Basement-Dwelling Losers. Independent.

Rattenkönig. 2019. Live at Recrucifying the Bastard 2019. Australibus Tenebris, Launceston, Tasmania.

Spear of Longinus 1995. Nazi Occult Metal. Independent. 2002. The Yoga of National Socialism. Vinland Winds, ID: VWR 002. 2004. Black Sun Society. Vinland Winds, ID: VWR 012.

2007. ... And the Swastikalotus. Forgotten Wisdom Productions, ID: FWP 038

\section{Videography}

GronSS, (2012), DeathKult Open Air Festival 2012 - DESTRÖYER 666 [Online video]. Available from: https://www.youtube.com/watch? $v=97 \mathrm{tX} z R 4 n 7 \mathrm{HE}$. Accessed: 17 February 2020.

Metal Down Under. 2014. Dir. Nick Calpakdjian. Australia: MG Distribution.

Interviews

Audrey Peyper. 2018. Interviewed by Benjamin Hillier, Hobart, 29 June. 